\title{
Effects of microcurrents in the boundary layer on the attachment of benthic heterotrophic nanoflagellates
}

\author{
Marlene Willkomm ${ }^{1,2}$, Annette Schlüssel ${ }^{1}$, Ellen Reiz ${ }^{1}$, Hartmut Arndt ${ }^{1, *}$ \\ ${ }^{1}$ Department of General Ecology and Limnology, Zoological Institute, University of Cologne, 50923 Cologne, Germany \\ ${ }^{2}$ Working Group Limnology, Institute of Ecology, Friedrich-Schiller-University Jena, 07745 Jena, Germany
}

\begin{abstract}
Surfaces in running water are covered by a boundary layer. Virtually nothing is known about the importance of water currents in the microenvironment of nanofauna. Many questions have been partially answered concerning the effect of surface topography on the hydrodynamics in the vicinity of macrofauna; however, investigations of the 2 to $5 \mu \mathrm{m}$ water layer where nanoprotists live have been neglected. In the present study, we show that the flow velocity at a distance of a few micrometres from the substrate is high enough to be very effective regarding the detachment of nanoprotists. We analysed the impact of flow velocity (detachment from substrate) on 8 nanoflagellate taxa (Entosiphon, Cercomonas, Codonosiga, Anthophysa, Bodo, Neobodo, Apusomonas, Spumella) with different abilities to crawl and attach to the surface. A Plexiglas disc was used to generate a defined flow velocity on the surface of a Petri dish microcosm. Laminar flow in the boundary layer was found between 0 and $700 \mu \mathrm{m}$ above the substratum. The effect of 4 different flow velocities on heterotrophic flagellates was investigated $\left(0.3,0.6,0.9\right.$ and $1.2 \mathrm{~m} \mathrm{~s}^{-1}$ at $5 \mathrm{~mm}$ above the substratum, corresponding to flow velocities of 0.001 to $0.004 \mathrm{~m} \mathrm{~s}^{-1}$ at $10 \mu \mathrm{m}$ above the substratum). The colourless, gliding euglenid Entosiphon sulcatum showed the highest resistance towards high flow velocities. Another species, the crawling cercomonad Cercomonas crassicauda, had the weakest attachment. Small changes in the micro-topography of the substrate (e.g. Ancylus shells) may significantly influence spatial distribution of nanoflagellates.
\end{abstract}

KEY WORDS: Heterotrophic nanoflagellates - Boundary layer • Microcurrents • Biofilm . Flow velocity $\cdot$ Topography

\section{INTRODUCTION}

It is commonly agreed that flow velocity can be an important factor for the structure and dynamics of aquatic ecosystems, especially in running waters and tidal regions (Battin et al. 2003a,b). It is assumed that the flow velocity decreases asymptotically from the surface towards the bottom. A few millimetres above the bottom, the flow velocity is very low (Ambühl 1959). This region is called the boundary layer and serves as a refuge for torrenticole macrofauna (Vogel 1981, Koehl 1984, Prandtl et al. 1984). Only a very few reports on the flow velocity in the microenvironment and the diffusion rates around microfauna and bacteria exist (e.g. Silvester \& Sleigh 1985, Lazier \& Mann 1989, Shimeta et al. 2001, 2002, Vopel et al. 2002, 2005, Willkomm 2006). Virtually nothing is known about the importance of water currents in the microenvironment of nanofauna. All of the questions that have partially been answered concerning the effect of surface topography on the hydrodynamics in the vicinity of macrofauna. Although some information is available on the effect of surface topography on hydrodynamics in the vicinity of macrofauna (e.g. Ambühl 1959, Statzner \& Holm 1989, Hunt 2004), the 2 to $5 \mu \mathrm{m}$ water layer in which nanoprotists live remains to be investigated. To 
understand microbial interactions on biofilms, several questions have to be answered, e.g. to what extent do water currents affect organisms in a size range of a few micrometres? Could the roughness of bacterial biofilms form a refuge for organisms of the nanofauna? Can meio- and macrofauna burrows and houses create hydrodynamically specific habitats for nanoflagellates?

We investigated the flow velocity in the micro-layer above the substrate and its impact on nanoflagellate species with different abilities to crawl and attach on the substrate in order to address at least some of the above-mentioned questions.

\section{MATERIALS AND METHODS}

Flow velocity measurements on a microscale. The effect of microcurrents on the attachment of heterotrophic flagellates was investigated in experimental microcosms. The microcosms consisted of Petri dishes with a diameter of $13.5 \mathrm{~cm}$. These were filled with about $75 \mathrm{ml}$ of flagellate cultures (WC medium is MBL; Guillard \& Lorenzen 1972) to reach a water column with a height of $5 \mathrm{~mm}$. By changing the current supply of a $12 \mathrm{~V}$ motor, the speed of a rotating Plexiglas disc on top of the fluid was regulated, generating a specific flow velocity in defined regions of the Petri dish (the regions had a distance of about $46 \mathrm{~mm}$ from the centre of the dish). To observe these regions, the bottom of each Petri dish contained 4 windows with cover slips $(50 \times 25 \mathrm{~mm})$ to allow observation of the surface-associated flagellates by inverse microscope at high magnifications (up to 400×; Zeiss Axiovert 100; Fig. 1). The inner surface of the Petri dish (including cover slips) was flush to avoid any disturbances of the water current. For identification of the flow velocity in microcosms, the fluid was spiked with a suspension of $10 \mu \mathrm{m}$ neutrally buoyant hollow glass spheres (cf. Røy 2003; kindly provided by Hans Røy, Max Planck Institute for Marine Microbiology, Bremen, Germany). Flow speed of particles was estimated from video image sequences of 50 frames $\mathrm{s}^{-1}$. This is a classical method of visualising the flow fields under laboratory conditions (e.g. Riedl \& Forstner 1968, Oakey et al. 2002). The flow velocity was determined in different layers of the water established by a calibrated fine drive of the microscope.

The flow velocities were determined in the different layers of the circular flow chambers between 0 and $5000 \mu \mathrm{m}$ above the substrate (Fig. 1). At a disc velocity of $0.3 \mathrm{~m} \mathrm{~s}^{-1}$, the flow velocity ranged between $0.001 \mathrm{~m}$ $\mathrm{s}^{-1}(0$ to $10 \mu \mathrm{m})$ and $0.3 \mathrm{~m} \mathrm{~s}^{-1}(5000 \mu \mathrm{m})$. In the layer between 0 and $700 \mu \mathrm{m}$, a linear increase of the flow velocity was detected. A slight increase of flow velocity

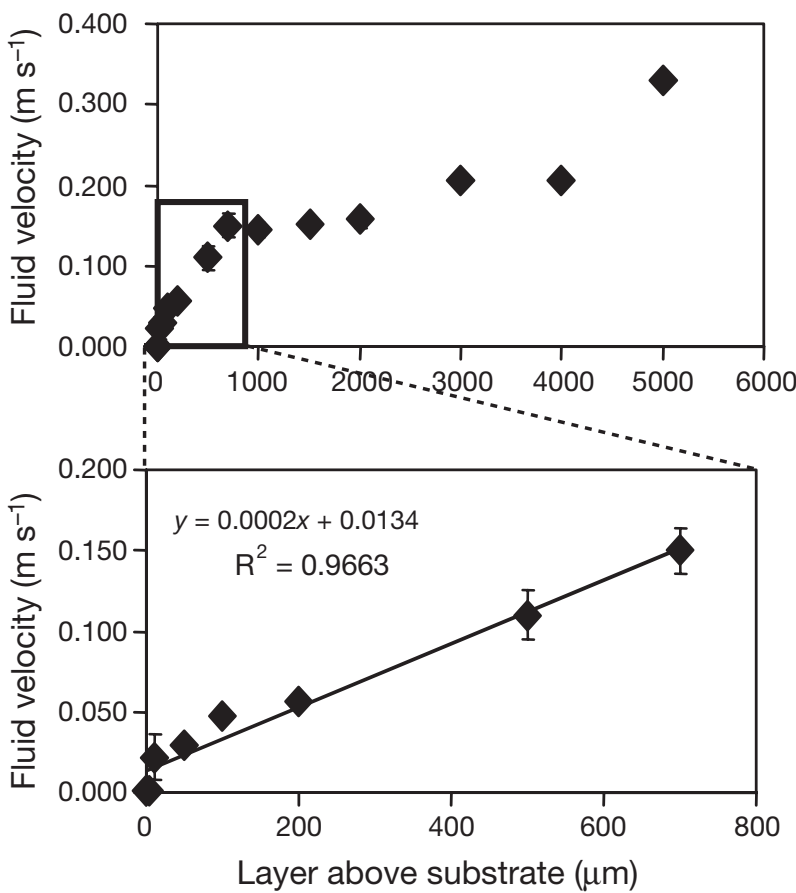

Fig. 1. Flow velocity at different layers of the microcosm (in $\mu \mathrm{m}$ above the substrate) at a speed of the rotating disc of $0.3 \mathrm{~m} \mathrm{~s}^{-1}$. Error bars indicate the standard deviation. The lower graph is an enlargement for the region of linear increase of flow velocity ( $n=2$ to 5 )

was recorded for the layer between about 1000 and $4000 \mu \mathrm{m}$ above the dish surface, while a linear approach to the velocity of the disc was registered in the upper layer (4000 to $5000 \mu \mathrm{m}$ above the dish surface).

Flagellate cultures. Eight different species of heterotrophic nanoflagellates (monoxenic cultures) were used in the experiments (Fig. 2). Two species formed colonies at the end of a stalk: Codonosiga botrytis (total length of the colony: 45 to $95 \mu \mathrm{m}$; Choanoflagellida; isolated from the Rhine River by M. Weitere) and Anthophysa vegetans (total length of the colony: 65 to $125 \mu \mathrm{m}$; Chrysomonadida; isolated from the Rhine River by M. Weitere). Spumella sp. (cell length: 3 to $7 \mu \mathrm{m}$; Chrysomonadida; isolated from Lake Schöhsee by A. P. Mylnikov) was attached to the substratum by a protoplasmid thread. The euglenid Entosiphon sulcatum (20 to $25 \mu \mathrm{m}$; obtained from CCAP 1220/1A), the apusomonad Apusomonas proboscidea (8 to $12 \mu \mathrm{m}$; isolated from a lake near Borok, Russia, by A. P. Mylnikov), the kinetoplastid Neobodo designis ( 4 to $7 \mu \mathrm{m}$; isolated from the Rhine River by M. Weitere) and the cercomonad Cercomonas crassicauda (15 to $20 \mu \mathrm{m}$; isolated from a lake near Borok, Russia, by A. P. Mylnikov) are tectic flagellates that glided over the surface of the Petri dish. The kineto- 


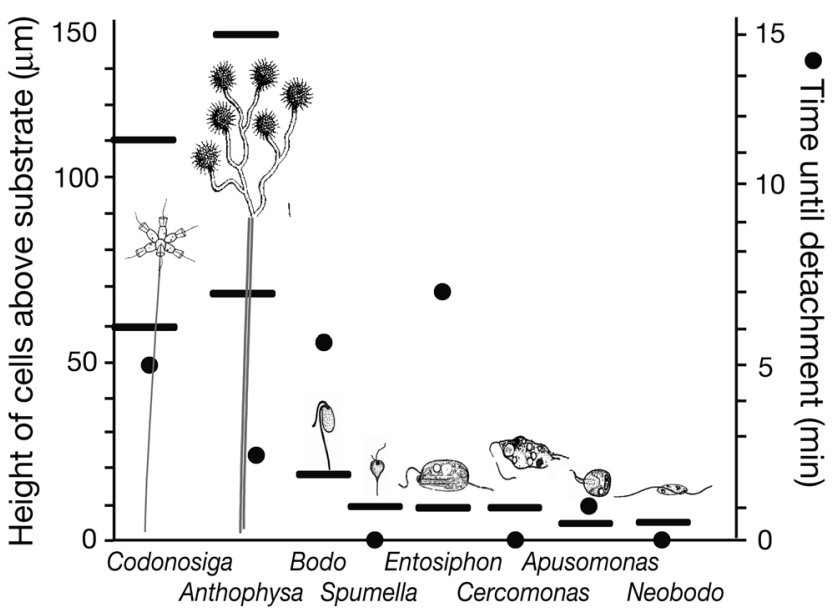

Fig. 2. Relationship between the morphology and the detachment time of 8 heterotrophic nanoflagellates. Horizontal bars indicate the mean distance of single cells from the substrate (for Codonosiga and Anthophysa a range is given for the colonies); black dots stand for the mean time until detachment at a disc velocity of $1.2 \mathrm{~m} \mathrm{~s}^{-1}$ (cf. Fig. 3)

plastid Bodo saltans (5 to $6 \mu \mathrm{m}$; isolated from a lake near Borok, Russia, by A. P. Mylnikov) was attached to the surface of the Petri dish by the tip of the posterior flagellum.

Effects of flow velocity on smooth surfaces. The 8 species of heterotrophic flagellates mentioned above, with different morphologies and types of attachment to the surface, were exposed in separate experiments to different flow velocities on a smooth surface (Petri dish). Flagellate cultures were inoculated to the Petri dish microcosms $12 \mathrm{~h}$ before the start of the experiments. Preliminary studies showed that this preincubation served as an adaptation time, allowing a comparative study of the different species. The flow velocity was increased stepwise with intervals of $0.1 \mathrm{~m}$ $\mathrm{s}^{-1}$ every $5 \mathrm{~s}$ until the target velocity was reached. At this point the investigation period started. During this 10 min period comparative data for all species were collected. The time until detachment (passive pull off) of flagellates was determined at flow velocities of 0.3 , $0.6,0.9$ and $1.2 \mathrm{~m} \mathrm{~s}^{-1}$ (measured at a height of $5 \mathrm{~mm}$ above the surface of the Petri dish). At the height of $10 \mu \mathrm{m}$ above the surface of the Petri dish, the flow velocities were $0.001,0.002,0.003$ and $0.004 \mathrm{~m} \mathrm{~s}^{-1}$. Then, 5 to 8 replicate experiments with different cultures of the same flagellate strain were carried out. The height of organisms indicated (Fig. 2) was estimated at conditions without flow using a calibrated fine drive of the microscope.

Effects of flow speed on the distribution of flagellates depending on surface topography. Two of the above-mentioned heterotrophic flagellates, Entosi- phon sulcatum and Cercomonas crassicauda, were introduced into Petri dishes with shells of the basommatophoran snail Ancylus fluviatilis (length: $3.1 \mathrm{~mm}$, width: $1.9 \mathrm{~mm}$, height: $1.1 \mathrm{~mm}$; average dimensions) glued on the bottom of the dishes. The shells were used to mimic the roughness of the biofilm due to the presence of macrofauna. A. fluviatilis is a typical inhabitant of biofilms in rivers (Nielsen 1950, Elser 1999), where most of the flagellates used in this study were isolated. The spatial distributions of the 2 flagellate species were investigated in the area behind the shells. This area was divided into 20 fields $(92 \times$ $100 \mu \mathrm{m})$. Experiments were carried out at a flow velocity of $0.3 \mathrm{~m} \mathrm{~s}^{-1}$ (at a height of $5 \mathrm{~mm}$ above the surface of the Petri dishes). The direction of the current and the flow velocity were determined in every field (methods see above). The abundance of the heterotrophic flagellates was determined every minute for each single field by an inverse microscope (videomicroscopy with a ZEISS Axiovert 100; $25 \times$ magnification). The average abundance of flagellates in each field was determined for a period of $10 \mathrm{~min}$. The maximum abundance in each experimental set up was considered as $100 \%$. Four replicate experiments were carried out for each species. Pearson rank correlation was used to analyse the correlation between abundance and flow velocity.

\section{RESULTS}

\section{Effects of flow velocity on nanoflagellates on smooth surfaces}

When the disc velocity changed from 0.1 to $1.4 \mathrm{~m}$ $\mathrm{s}^{-1}$, the flow velocity above the substrate changed from about 0.0003 to $0.0045 \mathrm{~m} \mathrm{~s}^{-1}$. The question arose whether these changes of more than an order of magnitude in flow velocities might affect the behaviour of nanoflagellates living close to the substrate. The 8 different nanoflagellate species were exposed to 5 different flow velocities, and the time until detachment was measured. All species differed significantly regarding their type of attachment, the substrate and the mean distance from the substrate (Fig. 2). Codonosiga botrytis and Bodo saltans withstood the maximal target time (10 $\mathrm{min})$ up to a velocity of $0.6 / 0.002 \mathrm{~m} \mathrm{~s}^{-1}$ (at a distance of either $5 \mathrm{~mm}$ or $10 \mu \mathrm{m}$ from the substrate; Fig. 3). At the highest velocity of $1.2 / 0.004 \mathrm{~m} \mathrm{~s}^{-1}$, Entosiphon sulcatum (7:25 min) reached the longest attachment time of all 8 flagellates, followed by B. saltans (5:53 min), $C$. botrylis (5:24 $\mathrm{min})$, Anthophysa vegetans (2:45 $\mathrm{min})$, Apusomonas proboscidea (1:35 min), Neobodo designis (0:31 min), Spumella sp. (0 min) and Cercomonas 
crassicauda (0 min). No species withstood the flow for the maximum target time of $10 \mathrm{~min}$ at the highest velocity. Spumella sp. and C. crassicauda showed the least resistance to the flow, numbers of attached specimens decreased very rapidly already when low flow velocities were applied (Fig. 3). There was no correlation between the distance of the individual flagellate cells from the substrate and the period of attachment (cf. Fig. 2).
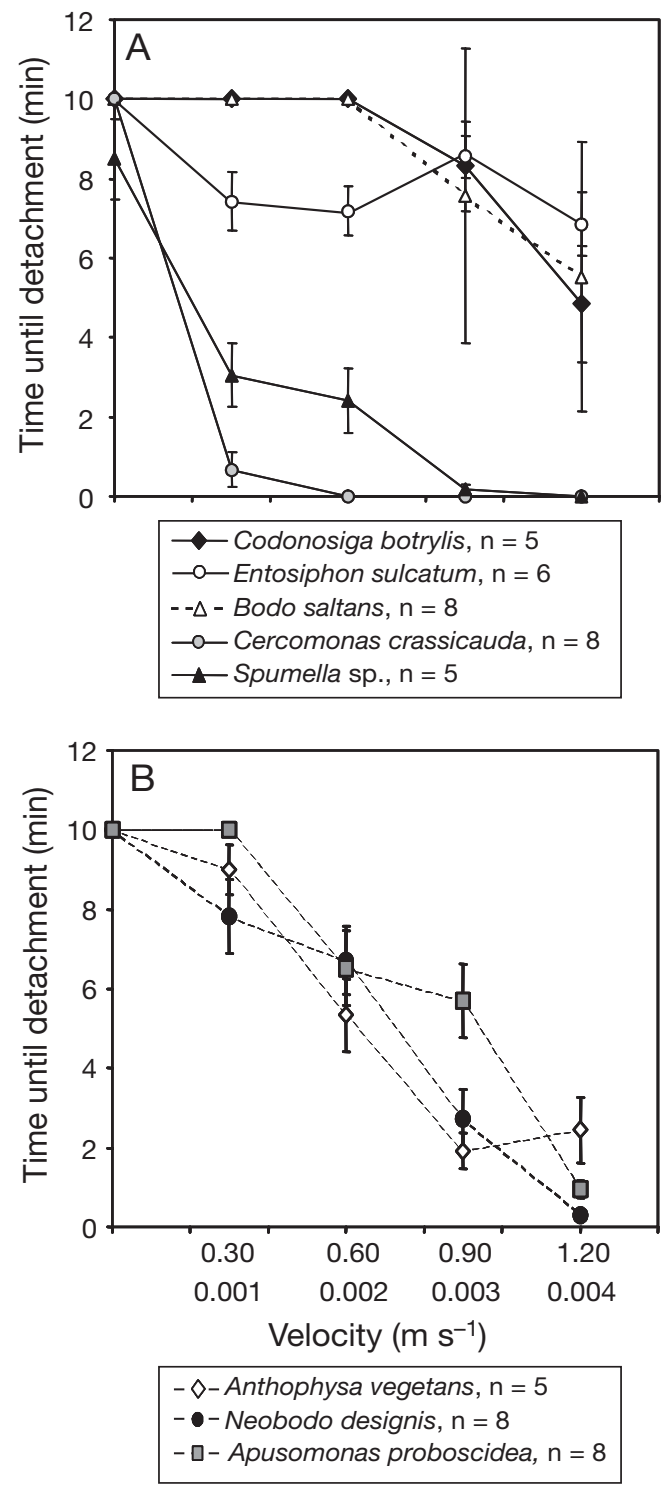

Fig. 3. Time until detachment of 8 different heterotrophic nanoflagellates at different flow velocities. The upper line of the abscissa gives the disc velocity $(5 \mathrm{~mm}$ above the substrate), while the lower line shows the corresponding flow velocities above the substrate ( 0 to $10 \mu \mathrm{m})$. The maximum investigation time was $10 \mathrm{~min}$ (A) Codonosiga botrylis, Entosiphon sulcatum, Bodo saltans, Cercomonas crassicauda and Spumella sp. and (B) Anthophysa vegetans, Neobodo designis and Apusomonas proboscidea

\section{Effects of flow velocity on the distribution of flagellates in relation to surface topography}

The effect of substrate topography in the microscale using shells of the snail Ancylus fluviatilis as a model was studied by analysing the distribution patterns of 2 flagellate species, Entosiphon sulcatum and Cercomonas crassicauda. The highest abundance of Entosiphon was found close to the shell, on the lee
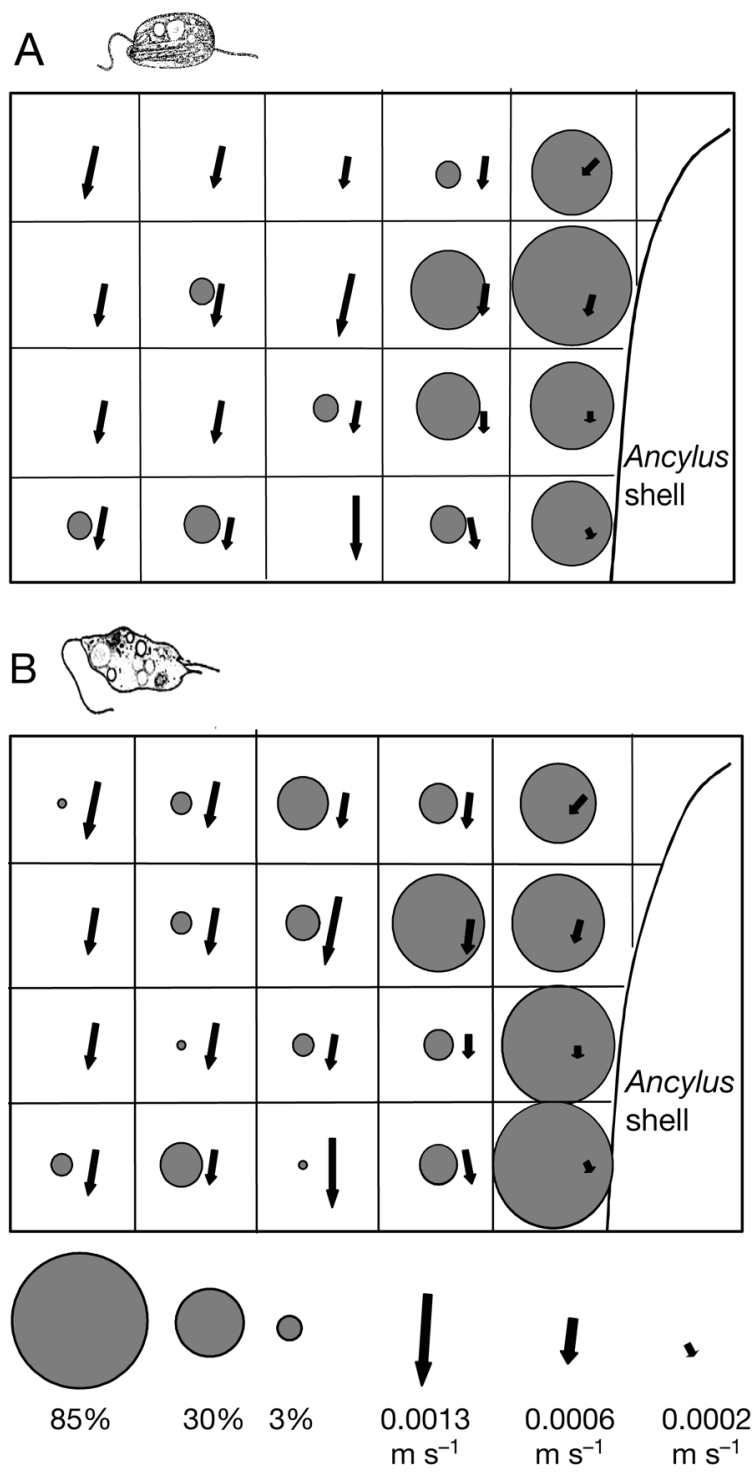

Fig. 4. (A) Entosiphon sulcatum and (B) Cercomonas crassicauda. Distribution behind an Ancylus shell exposed to flow for $10 \mathrm{~min}$ at a disc velocity of $0.3 \mathrm{~m} \mathrm{~s}^{-1}$ (mean of 4 experiments for both species). The diameter corresponds to the mean abundance in the fields of observation $(92 \times 100 \mu \mathrm{m})$. The arrows indicate the direction of the water current and the flow velocity above the substrate (in the 0 to $10 \mu \mathrm{m}$ layer) 
side, in the region where flow velocities were lowest. Cercomonas showed a similar distribution pattern (Fig. 4). There was a significant negative correlation $(p<0.05)$ between the abundance in the investigated fields of observation and the corresponding flow velocity.

\section{DISCUSSION}

We used glass slides as an artificial substrate in order to compare the different behaviours of heterotrophic nanoflagellate species. The addition of snail shells gave an idea of the potential effects of natural microtopographies on biofilms.

It is known that boundary layer flow characteristics in the sub-millimetre range may control pathways and magnitudes of material and gas exchange in the surface micro-layer of sediments that depend on the topography of the sediment surface (e.g. de Beer et al. 1994, 1996, Huettel et al. 2003, Røy et al. 2005). Even today, only very few studies have considered the effects on microfauna (e.g. Jakobsen 2001, Vopel et al. $2002,2005)$ and the influence of flow velocity on nanofauna $(<20 \mu \mathrm{m})$ has not yet been studied. Our microscopic technique gave us the opportunity to study the effect of flow on heterotrophic nanoflagellates in the laminar layer at intermediate Reynolds numbers (0.91 to 12.42; e.g. Smith 1975, Vogel 1981). We found significant effects on the attachment of heterotrophic flagellates already at very low flow velocities directly above the substrate $\left(0.0003\right.$ to $\left.0.004 \mathrm{~m} \mathrm{~s}^{-1}\right)$. We hypothesised that when such small flow velocities affect the occurrence of different nanoflagellates, small changes in the surface topography significantly influence the distribution patterns of flow-sensitive flagellates. Our experiments with Entosiphon and Cercomonas supported this hypothesis.

Another important result was that flow speeds of only a few millimetres $\mathrm{s}^{-1}$ had significantly different effects on the attachment of diverse flagellate species. Heterotrophic nanoflagellates may differ significantly with regard to their ecology and behaviour (Fenchel 1987, Arndt et al. 2000). The large Cercomonas species showed the lowest resistance towards the flow. This species lives generally within thick sediment layers and is not adapted to attach closely to the surface. Spumella has a low resistance as well. The thin plasmatic thread by which the single cells are attached to the substratum is suitable for attaching to suspended particles, but it does not withstand strong turbulence well. This is in agreement with observations of field biofilms (e.g. from rivers: M. Willkomm unpubl. data), where Spumella forms only a minor part of the biofilm community, in contrast to its major contribution to the plankton community. The calculation of drag according to Silvester \& Sleigh (1985) revealed a force of $1.6 \times$ $10^{-15} \mathrm{Nm}$ to be strong enough to detach Spumella from surface, while Bodo saltans seems to be adapted to withstand a 2 to 3 times higher drag force. The other investigated colourless chrysomonad Anthophysa is much better protected from high flow velocities. Colonies are attached via a flexible, excreted, extracellular polymer matrix. Though the flow velocity increases with increasing distance from the substrate, colonies are pressed by the flow towards the substrate, thus avoiding high flow velocities. Similar behaviour was described by Vopel et al. (2005) for peritrich colonies; when colonies are disrupted by high flow velocities, whole colonies or single cells break free and swim individually in the water column until they find more suitable habitats for attachment. Codonosiga, the other colony forming flagellates, has a much more rigid stalk made of proteinaceous substances, allowing this choanoflagellate species to withstand even high flow velocities. This species regularly populates biofilms of rivers in high densities (M. Willkomm \& M. Esser unpubl. data). The speciality of the kinetoplastid $B$. saltans is its strong attachment by the tip of the posterior flagellum, which explains its attachment even at relatively high flow velocities. This species occurs at extremely high turbulences due to artificial aeration in waste water treatment plants. The colourless, gliding, euglenid Entosiphon showed the highest resistance towards high flow velocities. It has a dorsoventrally flattened pellicle and a shape reminiscent of the body shape of torrenticolous insects. The shape seems to be optimised for a current-sheltered life on surfaces.

Statzner (1981) and Statzner \& Holm (1989) characterised the flow field around shells of Ancylus fluviatilis, a typical rheophilous organism of running waters (Elser 1999). Our experiments in the microscale showed that there is still water motion behind the shells, though at very low flow velocities. However, even these low flow velocities $\left(0.0002\right.$ to $0.002 \mathrm{~m} \mathrm{~s}^{-1}$ ) lead to characteristic micro-distributions of Entosiphon and Cercomonas accumulating in the region with lowest flow velocities $\left(0.0002\right.$ to $\left.0.0005 \mathrm{~m} \mathrm{~s}^{-1}\right)$. We conclude that the structure of biofilms and specific flow fields around objects and organisms inside the laminar flow region (e.g. sand grains, invertebrates, 3-dimensional structures of bacterial and/or algal biofilms) influences the micro-distribution and community structure of nano- and microfauna communities. We observed a behaviour typical of Entosiphon and Cercomonas in relationship to the flow velocity: at high flow velocities, the flagellates actively searched for areas of low flow velocity. Furthermore, in the absence of structures, both flagellates stopped movement at high flow velocities until detachment. For planktonic 
ciliates, it is known that they may react to flow velocities created, e.g. by the filter current of copepods (Jakobsen 2001).

The bulk of microbial activity in streams occurs on biofilms (Bryers 1982), and colonisation processes seem to be strongly influenced by surface microtopography, which, in turn, should govern the community structure of nano- and microfauna in lotic environments. Understanding the interactions between physical and biological processes in the micro-scale seems to be an important prerequisite in order to analyse microbial life in the water.

Acknowledgements. Sincere thanks go to H. Røy (Max Planck Institute for Marine Microbiology, Bremen) for helpful advice in the analysis of fluid dynamics. The study was supported by the German Research Foundation (DFG) through a PhD grant to M.W. (Graduiertenkolleg 266/2, speaker S. Halle, Jena) and a research grant to H.A. (SPP 1162 Aquashift, speaker U. Sommer, Kiel).

\section{LITERATURE CITED}

Ambühl H (1959) Die Bedeutung der Strömung als ökologischer Faktor. Schweiz Z Hydrol 21:133-264

Arndt H, Dietrich D, Auer B, Cleven EJ, Gräfenhan T, Weitere M, Mylnikov AP (2000) Functional diversity of heterotrophic flagellates in aquatic ecosystems. In: Leadbeater BSC, Green JC (eds) The flagellates. Taylor \& Francis, London, p 240-268

Battin TJ, Kaplan LA, Newbold JD, Cheng X, Hansen CME (2003a) Effects of current velocity on the nascent architecture of stream microbial biofilms. Appl Environ Microbiol 69:5443-5452

Battin TJ, Kaplan LA, Newbold JD, Hansen CME (2003b) Contributions of microbial biofilms to ecosystem processes in stream mesocosms. Nature 426:439-442

Bryers JD (1982) Processes governing primary biofilm formation. Bioengineering 24:2451-2476

de Beer D, Stoodley P, Roe F, Lewandowski Z (1994) Effects of biofilm structures on oxygen distribution and mass transport. Biotechnol Bioeng 43:1131-1138

de Beer D, Stoodley P, Lewandowski Z (1996) Liquid flow and mass transport in heterogeneous biofilms. Water Res 30: 2761-2765

Elser P (1999) Use of colonization baskets for the investigation of disturbance phenomena in streams under model conditions. Limnologica 29:120-127

Fenchel T (1987) Ecology of protozoa. Science Tech Publ, Madison, WI, and Springer, Berlin

Guillard RRL, Lorenzen CJ (1972) Yellow-green algae with chlorophyllide $c$. J Phycol 8:10-14

Huettel M, Røy H, Precht E, Ehrenhauss S (2003) Hydrodynamical impact on biogeochemical processes in aquatic

Editorial responsibility: Robert Sanders,

Philadelphia, Pennsylvania, USA sediments. Hydrobiologia 494:231-236

Hunt HL (2004) Effects of epibenthic predators in flow: transport and mortality of juveniles of the soft shell clam Mya arenaria. Mar Ecol Prog Ser 279:151-160

Jakobsen HH (2001) Escape response of planktonic protists to fluid mechanical signals. Mar Ecol Prog Ser 214:67-78

Koehl MAR (1984) How do benthic organisms withstand moving water? Am Zool 24:57-70

Lazier JRN, Mann KH (1989) Turbulence and the diffusive layers around small organisms. Deep-Sea Res 36: $1721-1733$

Nielsen A (1950) The torrential invertebrate fauna. Oikos 2: 176-196

Oakey J, Allely J, Marr DWM (2002) Laminar-flow-based separations at the microscale. Biotechnol Prog 18: $1439-1442$

Prandtl L, Oswatitsch K, Wieghardt K (1984) Führer durch die Strömungslehre. Friedr. Vieweg \& Sohn, Braunschweig

Riedl R, Forstner H (1968) Wasserbewegung im Mikrobereich des Benthos. Sarsia 34:163-188

Røy H (2003) Dynamic structure and function of the diffusive boundary layer at the seafloor. PhD dissertation, University of Bremen

Røy H, Huettel M, Jørgensen BB (2005) The influence of topography on the functional exchange surface of marine soft sediments, assessed from sediment topography measured in situ. Limnol Oceanogr 50:106-112

Shimeta J, Starczak VR, Ashiru OM, Zimmer CA (2001) Influences of benthic boundary-layer flow on feeding rates of ciliates and flagellates at the sediment-water interface. Limnol Oceanogr 46:1709-1719

Shimeta J, Amos CL, Beaulieu SE, Ashiru OM (2002) Sequential resuspension of protists by accelerating tidal flow: implications for community structure in the benthic boundary layer. Limnol Oceanogr 47:1152-1164

Silvester NR, Sleigh MA (1985) The forces on microorganisms at surfaces in flowing water. Freshw Biol 15:433-448

Smith IR (1975) Turbulence in lakes and rivers. Annu Rep Freshw Biol Assoc 29:1-79

Statzner B (1981) The relation between 'hydraulic stress' and microdistribution of benthic macroinvertebrates in a lowland running water system, the Schierenseebrooks (North Germany). Arch Hydrobiol 91:192-218

Statzner B, Holm TF (1989) Morphological adaptation of shape to flow: microcurrents around lotic macroinvertebrates with known Reynolds numbers at quasi-natural flow conditions. Oecologia 78:145-157

Vogel S (1981) Life in moving fluids - the physical biology of flow. Willard Grant Press, Boston, MA

Vopel K, Reick CH, Arlt G, Pöhn M, Ott JA (2002) Flow microenvironment of two marine peritrich ciliates with ectobiotic chemoautotrophic bacteria. Aquat Microb Ecol 29:19-28

Vopel K, Thistle D, Ott J, Bright M, Røy H (2005) Waveinduced H2S flux sustains a chemoautotrophic symbiosis. Limnol Oceanogr 50:128-133

Willkomm M (2006) Effect of weirs on the flagellate community in biofilms. Verh Int Verein Limnol 29:1600-1602

Submitted: October 2, 2006; Accepted: April 30, 2007

Proofs received from author(s): June 19, 2007 